\title{
Perceptions Towards Cross-Infection Control Measures - A cross sectional study among Dental Outpatients in Chennai
}

\author{
Neha Sharma $\mathrm{M}^{1}$ and Leelavathi $\mathrm{L}^{2}$ \\ ${ }^{1}$ Saveetha Dental College and Hospitals, Saveetha Institute of Medical \\ and Technical Sciences,Saveetha University, Chennai 600077, India. \\ ${ }^{2}$ Senior lecturer, Department of Public Health Dentistry, Saveetha Dental College and Hospitals, \\ Saveetha Institute of Medical and Technical Sciences, Saveetha University, Chennai 600077, India.
}

\section{ABSTRACT}

Dental care and dental profession is more prone for risk of infections. Most of them are not aware that they may be a carrier of infection, it may happen that the dentist meets a patient, in whom an earlier infection can be proven by serology, but the patient is not aware of it and the clinical signs and symptoms are missing, as well. In order to prevent the cross infection the dentist has to ensure the hygienic protection of both the patients and the health-care workers. Infection control measures have to be known by the dental care professional and have to be kept informed to the patient by the dental personnel. Hence the aim of this study is to assess the perception of dental outpatients toward cross infection control measures in Chennai. A cross-sectional descriptive study of a convenient sample of patients visiting the dental hospital. A structured, close-ended, self-administered online questionnaire was distributed among 155 patients. The questionnaire consisted of questions related to attitude, awareness, and perception of patients toward infection control measures. Data analysis included frequency distribution tables. The results of this study revealed that there were more female respondents (56\%) than the males (44\%) and the most commonly seen age group among the respondents was 17-35 years (48\%). It was also found that 82\% of the respondents believed that the usage of gloves and masks by the dentist was very important and 71\% of them stated that they would refuse to get treatment from a dentist who is not wearing gloves and a mask. Majority of the outpatients were more aware about the importance of gloves, masks, goggles in the prevention of cross infection. Excellent sterilization facilities should be established in dental practices to ensure patient safety.

KEY WORDS: DISINFECTION; GLOVES; INFECTION; MASKS; STERILISATION.

\section{ARTICLE INFORMATION}

*Corresponding Author: karleela81@gmail.com

Received 15th June 2020 Accepted after revision 8th August 2020

Print ISSN: 0974-6455 Online ISSN: 2321-4007 CODEN: BBRCBA

Thomson Reuters ISI Web of Science Clarivate Analytics USA and Crossref Indexed Journal

$$
\begin{aligned}
& \text { Clarivate } \\
& \text { Analytics }
\end{aligned}
$$

NAAS Journal Score 2020 (4.31) SJIF: 2020 (7.728)

A Society of Science and Nature Publication,

Bhopal India 2020. All rights reserved.

Online Contents Available at: http//www.bbrc.in/

Doi: http://dx.doi.org/10.21786/bbrc/13.7/73 


\section{INTRODUCTION}

The oral cavity is a unique environment which provides an ideal medium for bacterial growth. Microorganisms present in the oral cavity may be transmitted from person to person through aerosol, water contamination or surface contact (Prasanth et al., 2010). Procedures that have been performed with the use of dental handpieces cause aerosol formation which are commonly contaminated with blood, bacteria, fungi and viruses (Szymanska, 2007). Air-water syringes and turbines may disperse the saliva and microorganisms contained in the patient's mouth, thus contaminating surrounding air and surfaces (Castiglia et al., 2008).

Infection control practices are an important aspect in clinical dentistry as there is a huge increase in the prevalence of infectious diseases among the dental patients. The patients visiting dental clinics for their dental and oral health care may be healthy or suffering from various infectious diseases and many times, the patients may be carriers of infectious diseases that cannot be easily detected clinically (Deogade et al., 2016). Dental health care professionals (DHCPs) are at risk of infections caused by various microorganisms such as Mycobacterium tuberculosis, hepatitis B and hepatitis C viruses, staphylococci, streptococci, herpes simplex virus types 1, human immunodeficiency virus (HIV), mumps, influenza, and rubella (Singh et al., 2011).

Transmission of dental infection can occur through infected air droplets, blood, saliva, and instruments contaminated with secretions (Ibrahim et al., 2017). Infection control and occupational safety recommendations for oral health professionals in India was drafted in 2007 and giving an overview of the dental infection safety and control in India, it stated that the level of infection control in India is still in the early infant stage and way behind the United States and European countries (Abichandani and Nadiger, 2012).

Dental professionals' infection control practices depend on various factors such as knowledge and educational background, availability of required materials, access to required materials, costs, sociodemographic factors (Dagher et al., 2017). Routine use of barrier techniques such as gloves, masks, spectacles has been reported to be important in preventing the three routes of transmission (dentist to patient, patient to dentist, patient to patient) in dental clinics (Baseer et al., 2013). Wearing eye protection is another important consideration, since it protects the operator from aerosols, debris and potentially infective particles (Ebrahimi et al., 2012). Effective infection control is utmost important for providing high-quality dental care for patients and a safe working environment for those who work in dental healthcare facilities (Bommireddy et al., 2016).

To the best of the knowledge, there is no report in recent literature about people's perception towards crossinfection in Chennai. Increasing awareness of cross infection issues in dentistry among the general public will probably be an additional driving force in changing behaviour of dentists and reducing infective hazards (Monarca, 2000). We have successfully completed numerous epidemiological studies for the betterment of our community (Khatri et al., 2019; Manchery et al., 2019; Prabakar et al., 2018a, 2018b, 2018c; Shenoy et al., 2019; Vishnu Prasad et al., 2018). In this research we are studying/analyzing the perception of dental outpatients toward cross infection control measures. Thus the aim of this study is to assess the perception of dental outpatients toward cross infection control measures in Chennai.

\section{MATERIAL AND METHODS}

This study was conducted among patients attending a private dental college and hospital in Chennai. This study was approved by the institutional ethical committee. The inclusion criteria for the study were all patients attending for the dental needs in the out-patient department of a private dental institute. Those who were willing to participate for the study were included. Exclusion criteria were patients who were not willing to participate in the study and patients who had dental emergencies which needed immediate treatment.

An online questionnaire survey was created using Google forms. Study was done for a period of two weeks and the questionnaire was given to the randomly selected outpatients. The questionnaire contained 19 questions which included the patient's proforma and questions regarding different perceptions towards the cross infection control measures of a dental clinic. The validity of the questionnaire was purely based on content validity based on logical reasoning. The responses were collected during a one week period and the data were tabulated.

Figure 1: Bar graph representing the distribution of the sample size based on the age of the patients. $\mathrm{X}$ axis represents the age of the patients and $\mathrm{Y}$ axis represents the number of patients. From the graph, it is evident that a maximum of $48 \%$ of the patients were between 17-35 years, 35\% of them were between 36-55 years and only $17 \%$ were more than 55 years old.

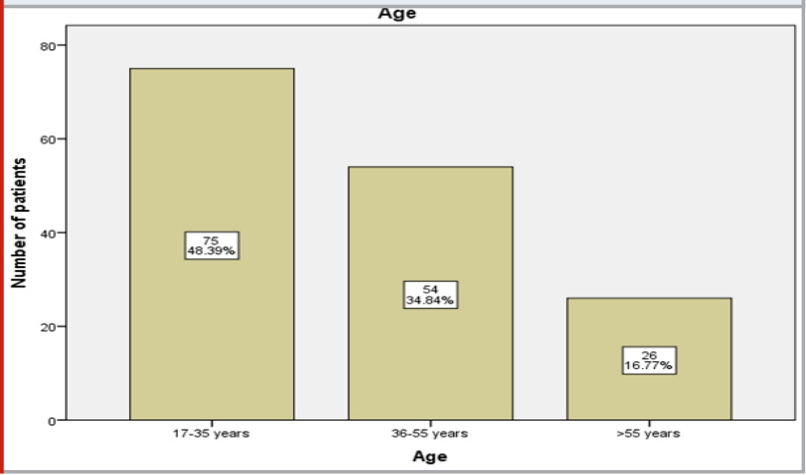

Statistical analysis: The tabulated data was imported to SPSS software by IBM for statistical analysis. Frequency of the number of questions answered was recorded. Chi square test was used to detect the significance ( $p$ 
value less than 0.05 was considered to be statistically significant).

Figure 2: Bar graph representing the distribution of the sample size based on the gender of the patients. $\mathrm{X}$ axis represents the gender of the patients and $\mathrm{Y}$ axis represents the number of patients. Purple colour denotes males and yellow colour denotes females. From the graph, it is evident that the maximum number of the patients were females $(56 \%)$ and the remaining were males $(44 \%)$. Hence the maximum number of patients taking up this survey were females.

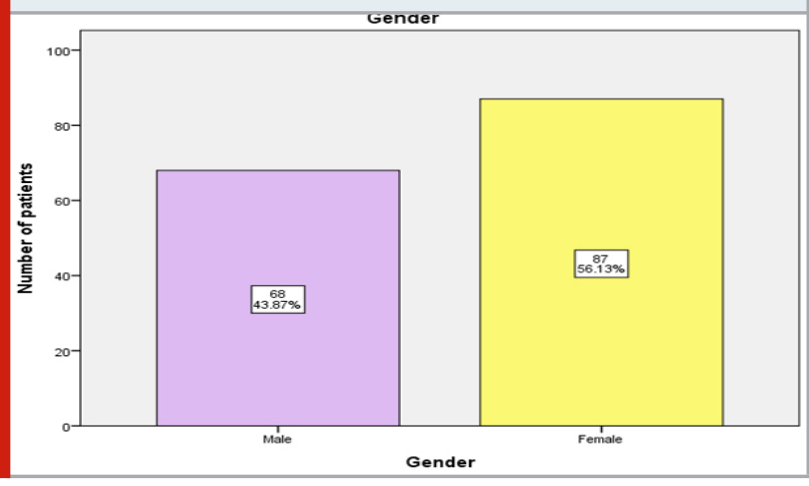

Figure 3: Bar graph representing the distribution of the sample size based on the educational qualification of the patients. $\mathrm{X}$ axis represents the educational qualification of the patients and $\mathrm{Y}$ axis represents the number of patients. From the graph, it is evident that the maximum number of the patients were undergraduates (67\%), 20\% of them completed school and 13\% of them were postgraduates. Hence the maximum number of patients taking up this survey were undergraduates.

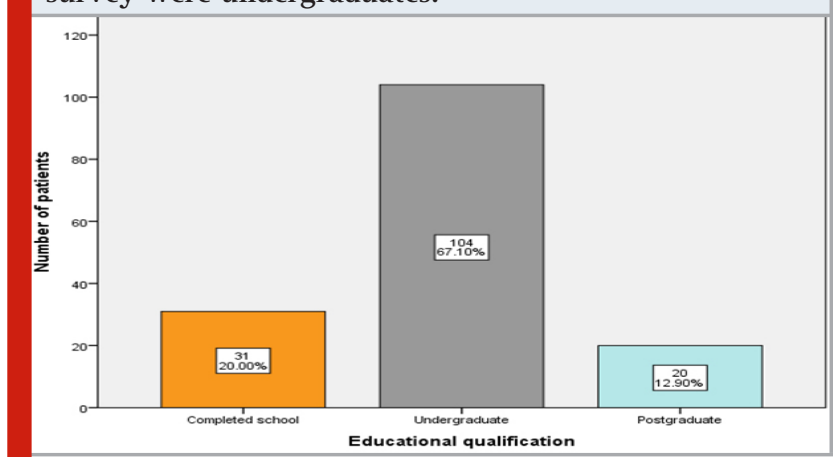

RESULTS AND DISCUSSION

About 155 patients took up this survey whose average age was 27 years [Figure 1]. About 87\% of the participants were females and 68\% were males [Figure 2]. 67\% of the participants were undergraduates, $20 \%$ of them completed school and 13\% of them were postgraduates [Figure 3]. 63\% of the total participants were unemployed and 37\% were employed [Figure 4]. It was found that $76 \%$ of the patients have visited a dental clinic in the past whereas $24 \%$ of them visited a dental clinic for the first time. A majority of 91\% patients believed that a dentist
Figure 4: Bar graph representing the distribution of the sample size based on the employment status of the patients. $\mathrm{X}$ axis represents the employment status of the patients and $\mathrm{Y}$ axis represents the number of patients. From the graph, it is evident that the maximum number of the patients were unemployed (63\%) whereas only $37 \%$ of them were employed.

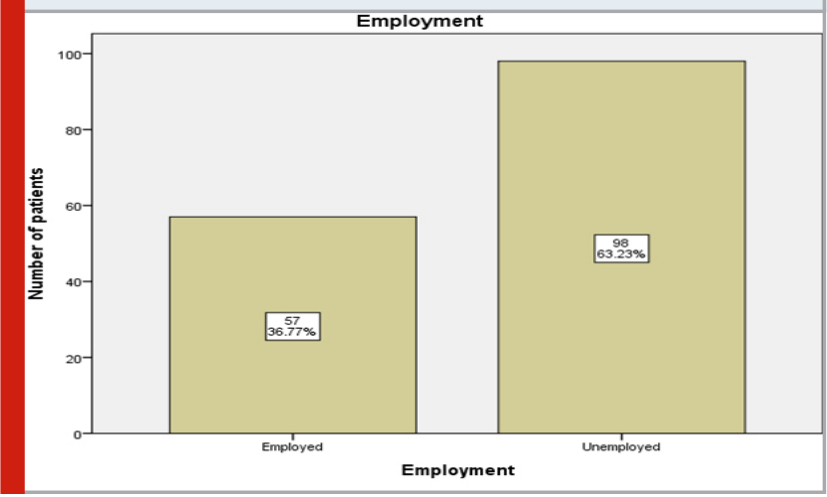

Figure 5: Bar graph representing the percentage of different responses for the question "Do you believe dentists should wear gloves while treating patients?". $\mathrm{X}$ axis represents the responses and $\mathrm{Y}$ axis represents the number of responses. Blue represents yes response and green represents no response. Higher percentage of respondents (91\%) accepted that a dentist should always wear gloves while treating a patient.

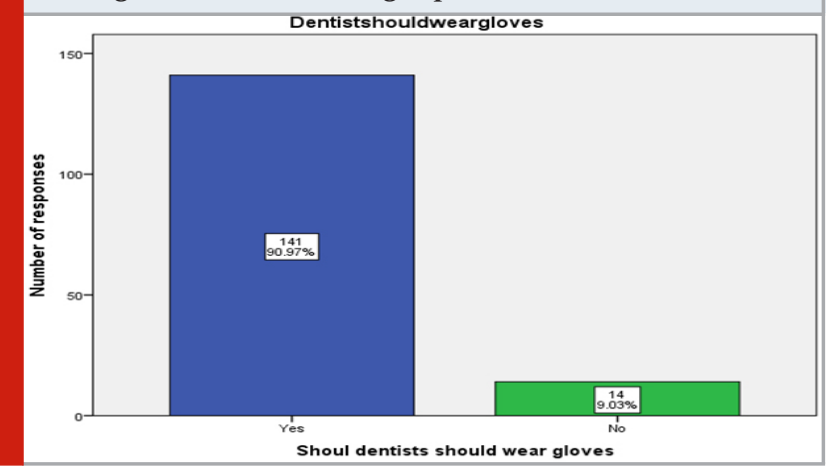

should wear gloves while treating patients [Figure 5]. About 85\% of the patients also believed that a dentist should wear a face mask while treating patients [Figure 6]. $67 \%$ of the patients agreed that a dentist should wear eye goggles while treating patients while $33 \%$ of them believed that it was not necessary for a dentist to wear eye goggles while treating patients [Figure 7].

About $82 \%$ of the patients believed that the usage of preventive measures like gloves and mask was very important, while $10 \%$ of them thought that it was not important for dentists to use preventive measures like gloves and masks [Figure 8]. $77.4 \%$ of the patients agreed that dentists can not treat more than one patient with the same pair of gloves [Figure 9]. 71\% of the patients refused to receive treatment from a dentist who is not wearing gloves and face mask [Figure 10]. 44.5\% of the patients refused to receive treatment from a dentist who 
is not immunized against Hepatitis B whereas 36\% of them were not aware of Hepatitis B infection [Figure 11]. $65.8 \%$ of the patients thought they can catch infection during a dental treatment while $17 \%$ of the patients had no idea about cross infection during a dental treatment [Figure 12]. 62\% of the patients were aware of the different sterilization methods used in dental clinics whereas 38\% of them were not aware of the different methods of sterilization [Figure 13].

Figure 6: Bar graph representing the percentage of different responses for the question "Do you believe dentists should wear face masks while treating patients?". $\mathrm{X}$ axis represents the responses and $\mathrm{Y}$ axis represents the number of responses. Blue represents yes response and green represents no response. Higher percentage of respondents (85\%) accepted that a dentist should always wear a mask while treating a patient.

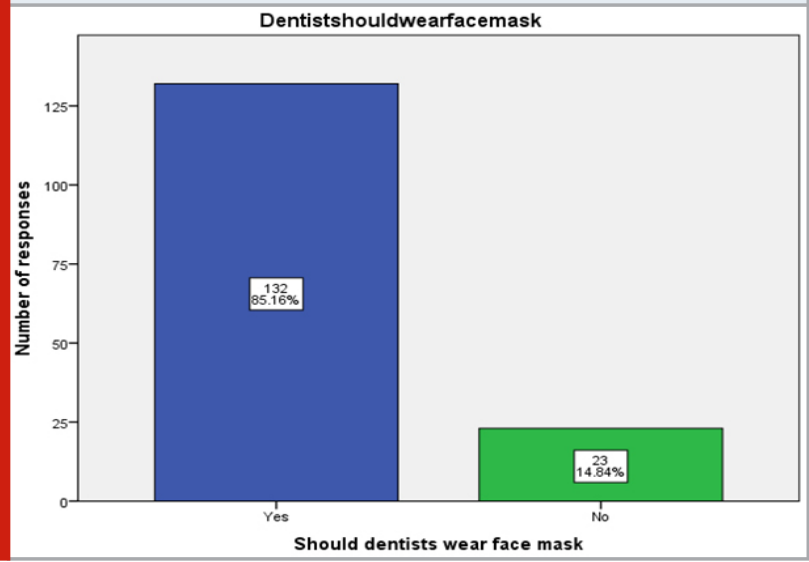

Figure 7: Bar graph representing the percentage of different responses for the question "Do you believe dentists should wear eye goggles while treating patients?". $\mathrm{X}$ axis represents the responses and $\mathrm{Y}$ axis represents the number of responses. Blue represents yes response and green represents no response. Higher percentage of respondents (67\%) accepted that a dentist should always wear eye goggles while treating a patient.

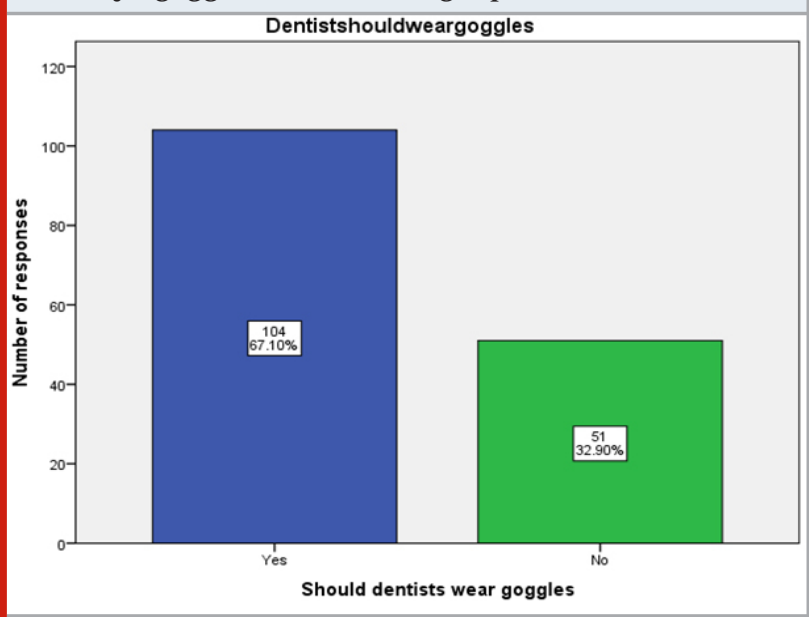

Figure 8: Bar graph representing the percentage of different responses for the question "According to you, how important is the usage of preventive measures like gloves and mask in a dental clinic?". $\mathrm{X}$ axis represents the responses and $\mathrm{Y}$ axis represents the number of responses. Higher percentage of respondents $(82 \%)$ believed that the usage of gloves and masks by the dentist is very important whereas $10 \%$ of the patients believed it was not so important.

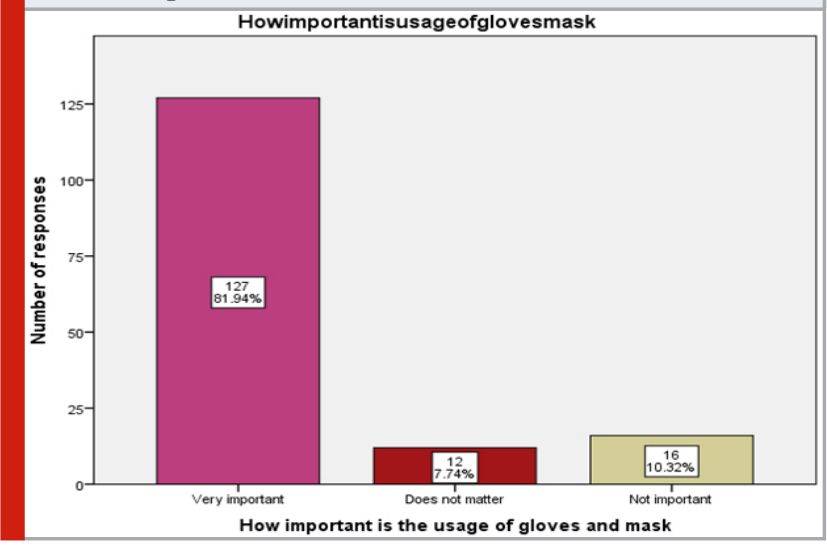

Figure 9: Bar graph representing the percentage of different responses for the question "Can a dentist treat more than one patient with the same pair of gloves?". $\mathrm{X}$ axis represents the responses and $\mathrm{Y}$ axis represents the number of responses. Blue represents yes response and green represents no response. Higher percentage of respondents $(77 \%)$ denied that a dentist can treat more than one patient with the same pair of gloves.

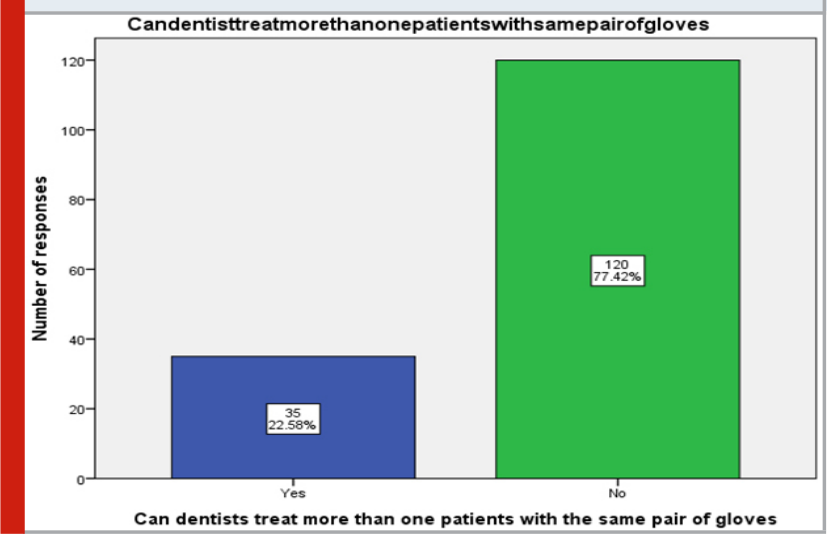

A majority of $69 \%$ of the patients believed that disinfection of dental chair, clinic and dental office is also required apart from just the sterilization of the instruments [Figure 14]. 69\% of the patients were aware of the biomedical waste management system whereas $31 \%$ of them were not aware [Figure 15]. When the patients were asked about the ways through which cross infection can occur, 41\% of them chose saliva, 37\% of them chose blood, 13.5\% of them chose other means and $9 \%$ of them had no idea about the different ways through which cross infection could occur [Figure 16]. About $72 \%$ of the patients were satisfied with the control 
measures taken at the dental clinic whereas 23\% of them were not satisfied [Figure 17].

Figure 10: Bar graph representing the percentage of different responses for the question "Would you refuse to receive treatment from a dentist who is not wearing gloves and face mask?". $\mathrm{X}$ axis represents the responses and $\mathrm{Y}$ axis represents the number of responses. Blue represents yes response and green represents no response. Higher percentage of respondents $(71 \%)$ stated that they would refuse to get treatment from a dentist who is not wearing gloves and a mask.

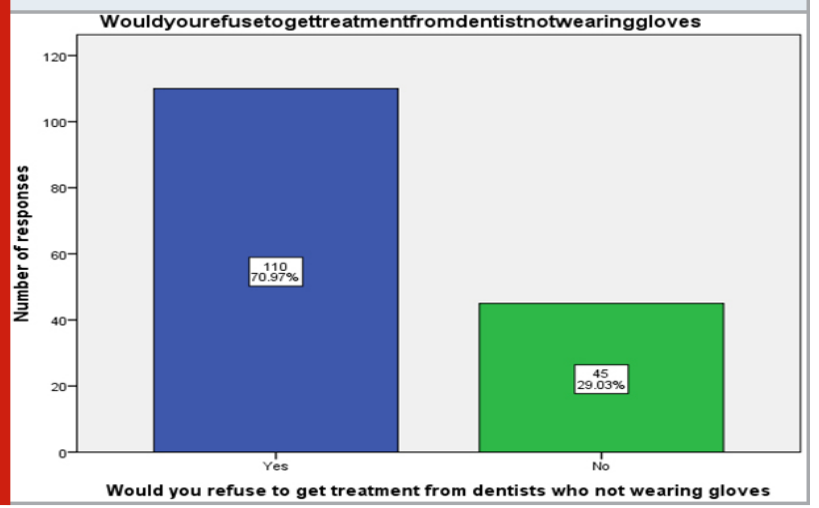

Figure 11: Bar graph representing the percentage of different responses for the question "Would you refuse to receive treatment from a dentist who is not immunized against Hepatitis B?". X axis represents the responses and $\mathrm{Y}$ axis represents the number of responses. Higher percentage of respondents $(44.5 \%)$ accepted that they would refuse to get treatment from a dentist who is not immunized against Hepatitis B whereas 36\% of the respondents had no idea about the Hepatitis infection.

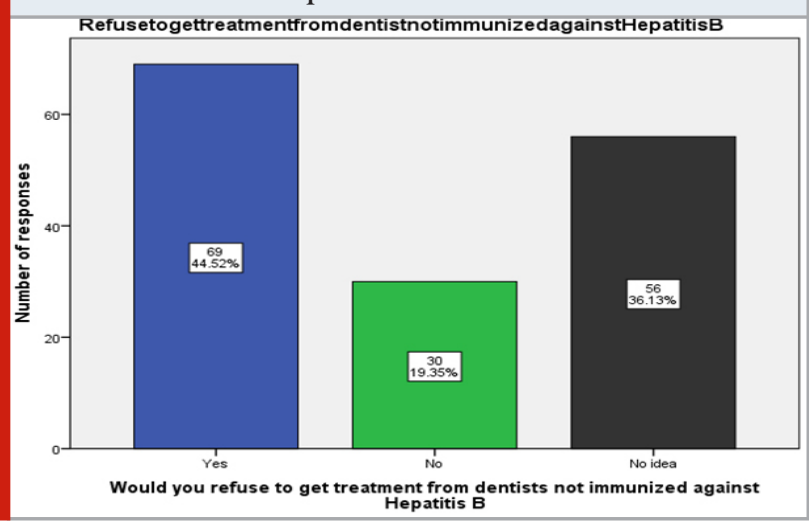

On analysing association, it was found that male patients (44\%) preferred not getting treatment from dentists who were not wearing gloves or masks, while the majority of females (29\%) denied it. This was found to be statistically significant (Chi square test; $p$ value $=0.001$-significant) [Figure 18]. It was also found that $42 \%$ of undergraduates and the patients who had completed school (20\%) were aware of the different sterilization methods used in the dental clinic. This was found to be statistically significant (Chi square test; $p$ value=0.001-significant) [Figure 19]
Patients who were undergraduates believed that cross infection spreads through blood (37\%), saliva (21\%) and any other means (10\%). 20\% of those who had completed school believed that cross infection spreads through saliva only which was also found to be statistically significant (Chi square test; $p$ value $=0.001$-significant) [Figure 20].

Figure 12: Bar graph representing the percentage of different responses for the question "Do you think you can catch infection during a dental treatment?". X axis represents the responses and $\mathrm{Y}$ axis represents the number of responses. Blue represents yes response, green represents no response and black represents no idea. Higher percentage of respondents (66\%) believed that they can catch an infection during a dental treatment whereas $17 \%$ of them had no idea about it.

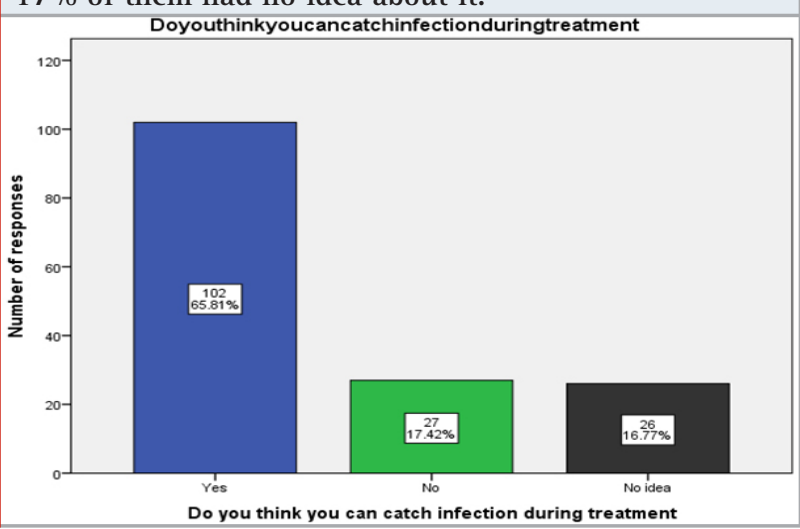

Figure 13: Bar graph representing the percentage of different responses for the question "Are you aware of the different sterilization methods used in dental clinics?". $\mathrm{X}$ axis represents the responses and $\mathrm{Y}$ axis represents the number of responses. Blue represents yes response and green represents no response. Higher percentage of respondents (62\%) were aware of the different sterilization methods used in a dental clinic.

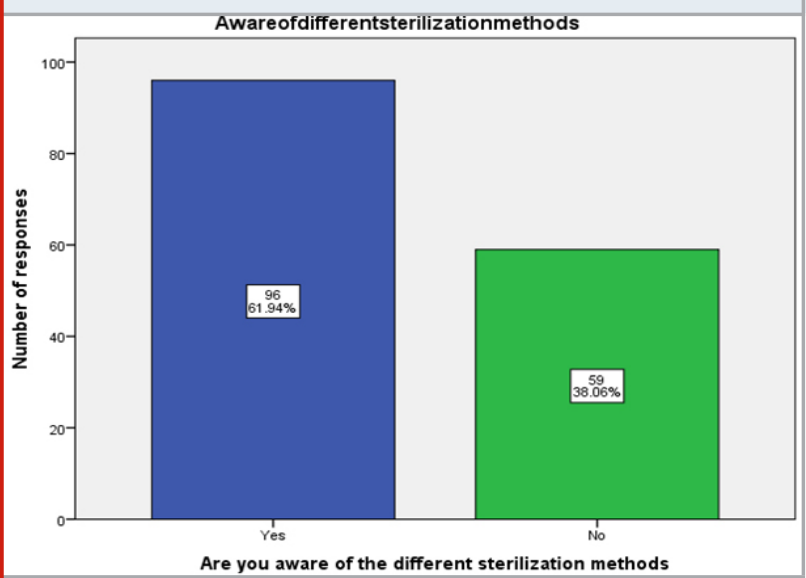

Maximum number of patients who were undergraduates (49\%) and those who had completed school (20\%) were aware of the biomedical waste management system whereas few undergraduates (18\%) and postgraduates 
(13\%) were not aware of this system. This difference was statistically significant (Chi-square test; $p$-value $=0.001$ - significant) Majority of patients who were undergraduates $(24.5 \%)$ and those who had completed school $(20 \%)$ refused to get treatment from dentists not immunized against hepatitis B whereas 23\% of undergraduate patients and 13\% of the postgraduate patients had no idea about this infection. This was found to be statistically significant (Chi-square test; p-value $=0.001$ - significant). $64.5 \%$ of patients who were undergraduates and those who had completed school $(20 \%)$ believed that a dentist cannot treat more than one patient with the same pair of gloves. This difference was statistically significant (Chi-square test; $p$-value $=0.001$ - significant) [Figure 21]. 51\% of patients who were undergraduates and $20 \%$ of patients who had completed school refused to get treatment from dentists not wearing gloves and face masks. This difference was statistically significant (Chi-square test; $\mathrm{p}$-value $=$ 0.001- significant).

Figure 14: Bar graph representing the percentage of different responses for the question "Apart from instrument sterilization, is disinfection of dental chair, clinic, dental office required?". X axis represents the responses and Y axis represents the number of responses. Blue represents yes response, green represents no response and black represents no idea. Higher percentage of respondents $(69 \%)$ believed that the disinfection of dental chairs and clinics was required whereas $20 \%$ of the respondents had no idea about it.

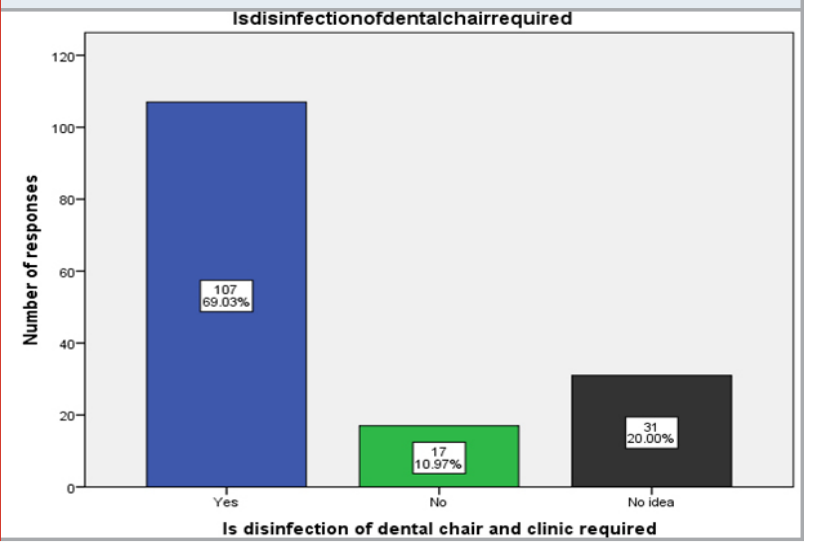

The concentration of bacterial aerosols appears to be highest during certain dental procedures that use high speed drill or procedures like ultrasonic scaling (Leggat and Kedjarune, 2001). The release of microorganisms into aerosols increases the microbial burden in the air and can lead to the contamination of all surfaces in a dental clinic. Because of the frequent aerosol generating procedures in dental practice, these aerosols can function as an important mode for infection transmission in dental clinics (Zemouri et al., 2020). The problem when studying cross-transmission is that it occurs everywhere, though transmission of pathogenic microorganisms does not necessarily result in an infectious disease of the host (Volgenant and de Soet, 2018). Microbial aerosols in the dental clinic may have different origins such as from the dental procedure, the dental staff or patients, but also from outside sources i.e. air, soil, and dust. Such aerosols can transfer microorganisms to the dental staff or patients (Kimmerle et al., 2012).

Figure 15: Bar graph representing the percentage of different responses for the question "Are you aware that clinical waste should be disposed through the Biomedical waste management system?". X axis represents the responses and $\mathrm{Y}$ axis represents the number of responses. Blue represents yes response and green represents no response. Higher percentage of respondents (69\%) were aware of the biomedical waste management system followed to dispose of medical waste.

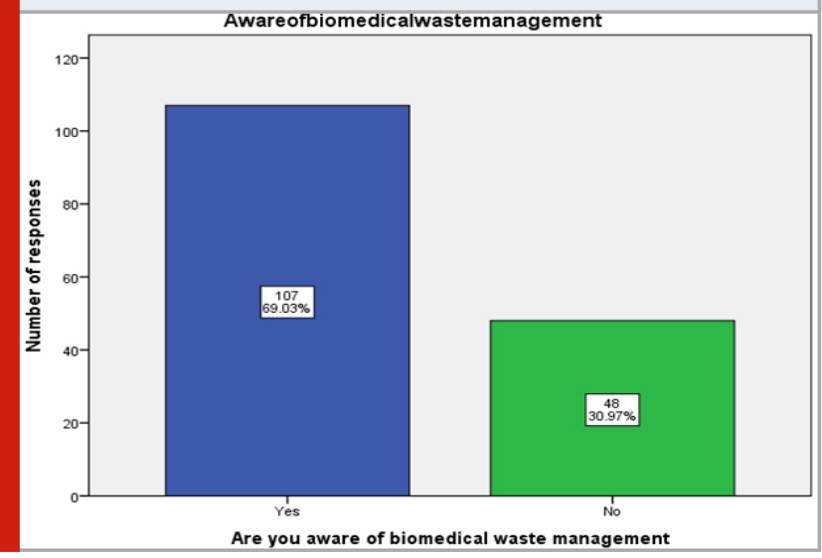

Figure 16: Bar graph representing the percentage of different responses for the question "What are all the ways cross infection can occur from one person to another in a dental setup?. $\mathrm{X}$ axis represents the responses and $\mathrm{Y}$ axis represents the number of responses. Higher percentage of respondents (41\%) thought that cross infection occurs through saliva, 37\% of them chose blood, and $9 \%$ of the respondents had no idea about the means through which cross infection might occur.

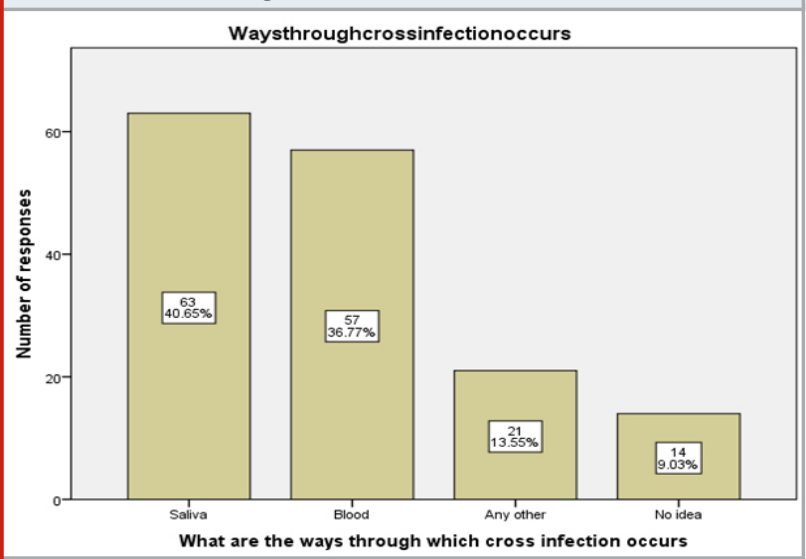

Sterilisation is a procedure that destroys pathogenic and nonpathogenic living organisms in a vegetative form or spore present on the surface of the material. An item or product that is free of living microorganisms is defined as sterile (Laneve et al., 2019). It is essential to ensure that all the microorganisms are killed during the sterilization 
process. Thus, the quality control is a significant part of the sterilization procedure (Sheth et al., 2017). Hence dentists and their staff should treat every patient as a potential risk, and implement all barrier techniques, including routine glove and mask use (Burke, 1990).

Figure 17: Bar graph representing the percentage of different responses for the question "Are you satisfied with the control measures taken for cross infection among patients?". $\mathrm{X}$ axis represents the responses and $\mathrm{Y}$ axis represents the number of responses. Blue represents yes response and green represents no response. Higher percentage of respondents $(71 \%)$ were satisfied with the control measures taken in the dental clinic during their visit.

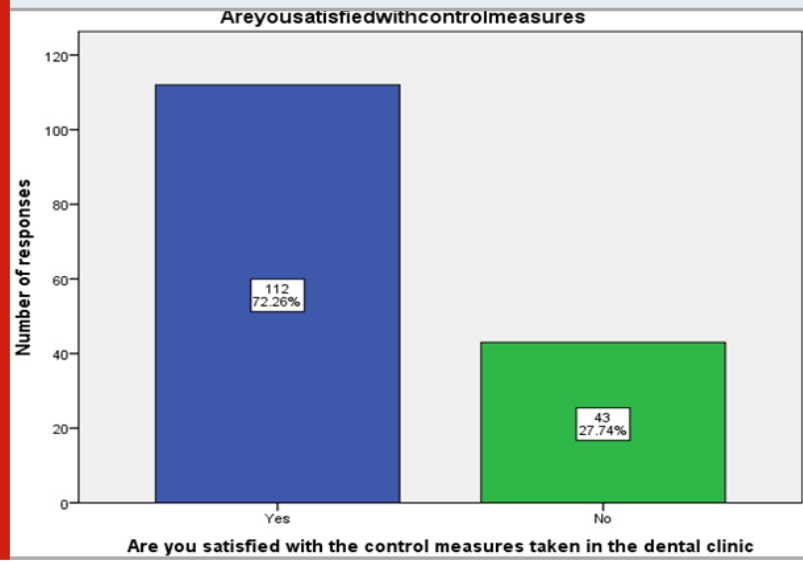

Figure 18: Bar graph representing the association based on gender of patients with the responses for the question "Would you refuse to receive treatment from a dentist who is not wearing gloves and face mask?". (X-axis represents the responses to the question and $\mathrm{Y}$-axis represents the number of responses). All the male participants (100\%) preferred not getting treatment from dentists who are not wearing gloves or masks, while only $48.28 \%$ of female participants denied getting treated from dentists who were not wearing gloves, suggesting males were more aware about the importance of gloves in infection control and this was statistically significant (Chi-square test; $p$-value $=0.001$ - significant)

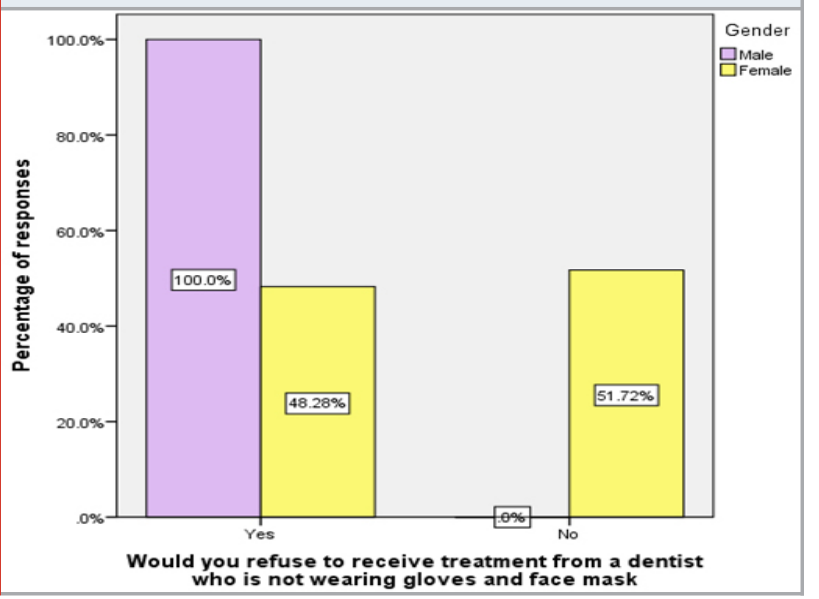

Figure 19: Bar graph representing the association based on educational qualification of patients with the responses for the question "Are you aware of the different sterilization methods used in dental clinics?". (X-axis represents the responses to the question and $\mathrm{Y}$-axis represents the number of responses). All the patients who had completed schooling $(100 \%)$ were aware of the different sterilization methods used in dental clinic whereas only $62.5 \%$ of the patients who were undergraduates were aware of the different sterilisation methods, proving that patients who had only completed schooling were more aware about the sterilisation methods and this was statistically significant (Chi-square test; $\mathrm{p}$-value $=0.001$ - significant).

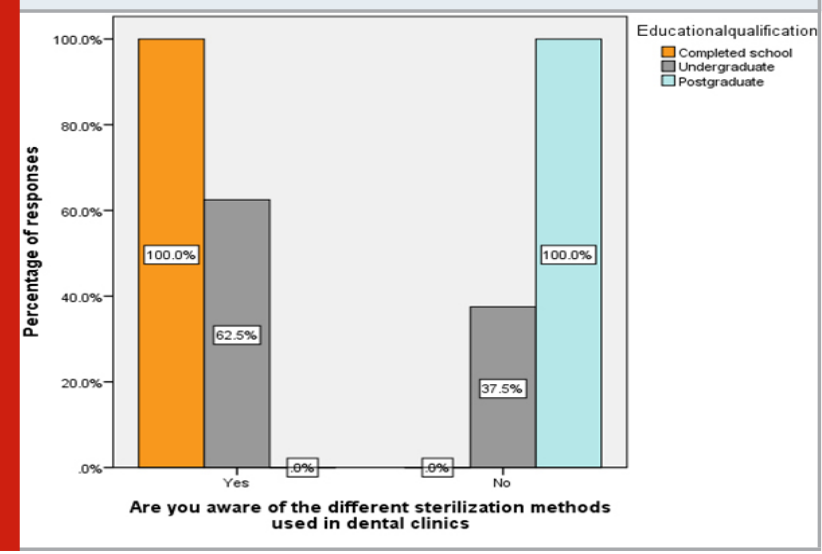

Figure 20: Bar graph representing the association based on educational qualification of patients with the responses for the question "What are all the ways cross infection can occur from one person to another in a dental setup?". $(\mathrm{X}$-axis represents the responses to the question and $\mathrm{Y}$-axis represents the number of responses). All the patients who had completed schooling (100\%) believed that cross infection might occur through saliva, whereas a maximum of $55 \%$ of the patients who were undergraduates believed that cross infection might occur through blood. This difference was found to be statistically significant (Chisquare test; $p$-value $=0.001$ - significant).

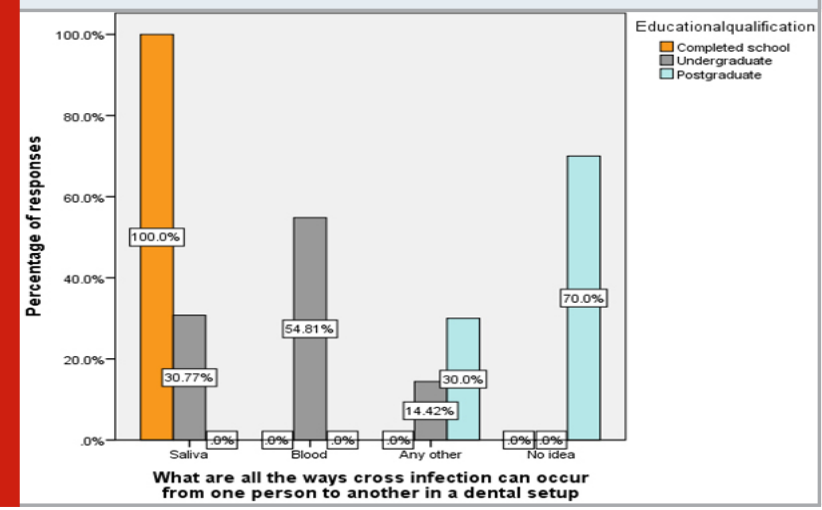

In this present study we found that the majority of the patients were females (56\%) and remaining were males $(44 \%)$. This is supported by a previous study which states the majority of the patients were females (62\%) 
(Deogade et al., 2016). We also found that the majority of 91\% of the patients believed that a dentist should wear protective gloves while treating patients. This is in concordance with studies done by Otuyemi et al and Sofola et al which state that the maximum number of patients (89\% and 99\% respectively) regarded the use of gloves as necessary during treatment (Otuyemi et al., 2001) (Sofola et al., 2005). Our study also revealed that $85 \%$ of the patients believed that dentists should wear face masks while treating a patient. This is in concordance with a study where the majority of patients (72.4\%) agreed that dentists should routinely wear face masks (Mousa et al., 1997).

Figure 21: Bar graph representing the association based on educational qualification of patients with the responses for the question "Can a dentist treat more than one patient with the same pair of gloves?". (X-axis represents the responses to the question and $\mathrm{Y}$-axis represents the number of responses). All the patients who had completed schooling $(100 \%)$ accepted that a dentist can treat more than one patient with the same pair of gloves whereas a maximum of $96 \%$ of the undergraduate patients and 100\% of the postgraduate patients stated that a dentist cannot treat more than one patient with the same pair of gloves. This was found to be statistically significant (Chi-square test; $\mathrm{p}$-value $=0.001$ - significant).

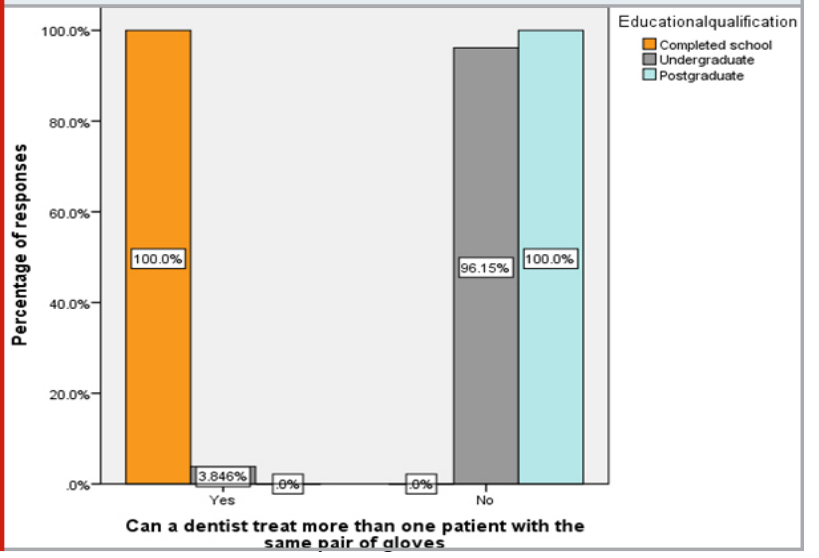

Another study by Samaranayake et al stated that the practice of wearing a face mask by the dentist was overwhelmingly approved by the survey population (Samaranayake and McDonald, 1990). In our study we also found that $82 \%$ of the total survey population agreed that a dentist should wear both mask and gloves while treating a patient. This is supported by a study done by Bowden et al stated that 50\% of the participants believed that a dentist should routinely wear both gloves and mask while doing a procedure (Bowden et al., 1989). In this present study it was found that $67 \%$ of the participants agreed that use of eye goggles by the dentist was necessary. This result is contradicted by a study which states that only $31 \%$ of the total respondants believed that dentists should always wear goggles when treating patients.
To date, there have been no population-based reports of public perceptions of dental cross-infection control in Chennai. This study aimed to clarify issues and provide data on public perceptions of cross-infection control in dentistry in Chennai. A limitation of this study was that it was a unicentred study and to ascertain the results of this study and to increase the level of significance, the sample size and the geographic area of coverage should be extended to more dental institutions in Chennai. When properly used, disinfection and sterilization can ensure the safe use of invasive and noninvasive dental devices. The method of disinfection and sterilization depends on the intended use of the dental device.

\section{CONCLUSION}

Within the limit of the study, it was found that the majority of the patients agreed that it was important for dentists to wear protective measures like gloves and masks while treating a patient, showing a high level of awareness about the risk of cross infection among this population.

\section{ACKNOWLEDGEMENTS}

The authors would like to acknowledge the help and support rendered by the Department of Research of the institution and the management for their constant assistance with the research.

\section{Conflict of Interest: Nil}

\section{REFERENCES}

Abichandani, S., Nadiger, R., 2012. Cross contamination in dentistry: A comprehensive overview. Journal of Education and Ethics in Dentistry.

Baseer, M.A., Rahman, G., Yassin, M.A., 2013. Infection control practices in dental school: A patient perspective from Saudi Arabia. Dent. Res. J. 10, 25-30.

Bommireddy, V., Pachava, S., Sanikommu, S., Vinnakota, N., Talluri, D., Ghanta, B., 2016. Infection control measures among dental practitioners in a Southern state of India: A cross-sectional study. Journal of Indian Association of Public Health Dentistry.

Bowden, J.R., Scully, C., Bell, C.J., Levers, H., 1989. Cross-infection control: attitudes of patients toward the wearing of gloves and masks by dentists in the United Kingdom in 1987. Oral Surg. Oral Med. Oral Pathol. 67, 45-48.

Burke, F.J., 1990. Use of non-sterile gloves in clinical practice. J. Dent. 18, 79-89.

Castiglia, P., Liguori, G., Montagna, M.T., Napoli, C., Pasquarella, C., Bergomi, M., Fabiani, L., Monarca, S., Petti, S., SItI Working Group Hygiene in Dentistry, 2008. Italian multicenter study on infection hazards during dental practice: control of environmental microbial contamination in public dental surgeries. BMC Public Health 8, 187.

Dagher, J., Sfeir, C., Abdallah, A., Majzoub, Z., 2017. Infection Control Measures in Private Dental Clinics in 
Lebanon. Int. J. Dent. 2017, 5057248.

Deogade, S., Mantri, S., Sumathi, K., Dube, G., Rathod, J., Naitam, D., 2016. Perceptions of dental outpatients toward cross-infection control measures in Jabalpur city. Journal of Indian Association of Public Health Dentistry.

Ebrahimi, M., Ajami, B.M., Rezaeian, A., 2012. Longer years of practice and higher education levels promote infection control in Iranian dental practitioners. Iran. Red Crescent Med. J. 14, 422-429.

Ibrahim, N.K., Alwafi, H.A., Sangoof, S.O., Turkistani, A.K., Alattas, B.M., 2017. Cross-infection and infection control in dentistry: Knowledge, attitude and practice of patients attended dental clinics in King Abdulaziz University Hospital, Jeddah, Saudi Arabia. Journal of Infection and Public Health.

Khatri, S.G., Madan, K.A., Srinivasan, S.R., Acharya, S., 2019. Retention of moisture-tolerant fluoride-releasing sealant and amorphous calcium phosphate-containing sealant in 6-9-year-old children: A randomized controlled trial. J. Indian Soc. Pedod. Prev. Dent. 37, 92-98.

Kimmerle, H., Wiedmann-Al-Ahmad, M., Pelz, K., Wittmer, A., Hellwig, E., Al-Ahmad, A., 2012. Airborne microbes in different dental environments in comparison to a public area. Archives of Oral Biology.

Laneve, E., Raddato, B., Dioguardi, M., Di Gioia, G., Troiano, G., Lo Muzio, L., 2019. Sterilisation in Dentistry: A Review of the Literature. Int. J. Dent. 2019, 6507286.

Leggat, P.A., Kedjarune, U., 2001. Bacterial aerosols in the dental clinic: a review. International Dental Journal.

Manchery, N., John, J., Nagappan, N., Subbiah, G., Premnath, P., 2019. Remineralization potential of dentifrice containing nanohydroxyapatite on artificial carious lesions of enamel: A comparative in vitro study. Dent. Res. J. 16, 310.

Monarca, S., 2000. Evaluation of environmental bacterial contamination and procedures to control cross infection in a sample of Italian dental surgeries. Occupational and Environmental Medicine.

Mousa, A.A., Mahmoud, N.M., Tag El Din, A.M., 1997. Knowledge and attitudes of dental patients towards cross-infection control measures in dental practice. EMHJ - Eastern Mediterranean Health Journal, 3 (2), 263-273, 1997.

Otuyemi, O.D., Oginni, A.O., Ogunbodede, E.O., Oginni, F.O., Olusile, A.0., 2001. Patients' attitudes to wearing of gloves by dentists in Nigeria. East Afr. Med. J. 78, 220-222.

Prabakar, J., John, J., Arumugham, I.M., Kumar, R.P., Sakthi, D.S., 2018a. Comparing the Effectiveness of Probiotic, Green Tea, and Chlorhexidine- and Fluoride- containing Dentifrices on Oral Microbial Flora: A Double-blind, Randomized Clinical Trial. Contemp. Clin. Dent. 9, 560-569.

Prabakar, J., John, J., Arumugham, I.M., Kumar, R.P., Sakthi, D.S., 2018b. Comparative Evaluation of the Viscosity and Length of Resin Tags of Conventional and Hydrophilic Pit and Fissure Sealants on Permanent Molars: An Study. Contemp. Clin. Dent. 9, 388-394.

Prabakar, J., John, J., Arumugham, I.M., Kumar, R.P., Srisakthi, D., 2018c. Comparative Evaluation of Retention, Cariostatic Effect and Discoloration of Conventional and Hydrophilic Sealants - A Single Blinded Randomized Split Mouth Clinical Trial. Contemp. Clin. Dent. 9, S233-S239.

Prasanth, T., Mandlik, V.B., Kumar, S., Jha, A.K., Kosala, M., 2010. Evaluation of Aerosol and Water Contamination and Control of Cross Infection in Dental Clinics. Medical Journal Armed Forces India.

Samaranayake, L.P., McDonald, K.C., 1990. Patient perception of cross-infection prevention in dentistry. Oral Surg. Oral Med. Oral Pathol. 69, 457-460.

Shenoy, R.P., Salam, T.A.A., Varghese, S., 2019. Prevalence and Clinical Parameters of Cervical Abrasion as a Function of Population, Age, Gender, and Toothbrushing Habits: A Systematic Review. World Journal of Dentistry 10, 470-480.

Sheth, N.C., Rathod, Y.V., Shenoi, P.R., Shori, D.D., Khode, R.T., Khadse, A.P., 2017. Evaluation of new technique of sterilization using biological indicator. J. Conserv. Dent. 20, 346-350.

Singh, A., Purohit, B.M., Bhambal, A., Saxena, S., Singh, A., Gupta, A., 2011. Knowledge, Attitudes, and Practice Regarding Infection Control Measures Among Dental Students in Central India. Journal of Dental Education.

Sofola, 0.0., Uti, 0.G., Onigbinde, 0.0., 2005. Public perception of cross-infection control in dentistry in Nigeria. Int. Dent. J. 55, 383-387.

Szymcska, J., 2007. Dental bioaerosol as an occupational hazard in a dentist's workplace. Ann. Agric. Environ. Med. 14, 203-207.

Vishnu Prasad, S., Kumar, M., Ramakrishnan, M., Ravikumar, D., 2018. Report on oral health status and treatment needs of 5-15 years old children with sensory deficits in Chennai, India. Spec. Care Dentist. 38, 58-59.

Volgenant, C.M.C., de Soet, J.J., 2018. Cross-transmission in the Dental Office: Does This Make You Ill? Curr Oral Health Rep 5, 221-228.

Zemouri, C., Volgenant, C.M.C., Buijs, M.J., Crielaard, W., Rosema, N.A.M., Brandt, B.W., Laheij, A.M.G.A., De Soet, J.J., 2020. Dental aerosols: microbial composition and spatial distribution. J. Oral Microbiol. 12, 1762040. 